\title{
Blatant Dehumanization is Not Influenced by Dual Identity Labels: Evidence from the Canadian Context
}

\author{
Carl Michael Galang ${ }^{1}$, Michael $\mathrm{Ku}^{1,2} \&$ Sukhvinder S. Obhi ${ }^{1}$ \\ ${ }^{1}$ Social Brain, Body and Action Lab, Department of Psychology, Neuroscience and Behaviour, McMaster \\ University, Canada \\ ${ }^{2}$ Faculty of Medicine, University of Ottawa, Canada \\ Correspondence: Carl Michael Galang, Social Brain, Body and Action Lab, Department of Psychology, \\ Neuroscience and Behaviour, McMaster University, Canada \& Sukhvinder S. Obhi, Social Brain, Body and \\ Action Lab, Department of Psychology, Neuroscience and Behaviour, McMaster University, Canada.
}

Received: October 5, 2021

Accepted: October 29, 2021

Online Published: November 22, 2021

doi:10.5539/ijps.v13n4p62

URL: https://doi.org/10.5539/ijps.v13n4p62

\begin{abstract}
Blatant dehumanization has been shown to be prevalent in modern society. However, little work has explored the possible ways in which blatant dehumanization may be attenuated. The current study addresses this gap in the literature by exploring if activating a dual identity attenuates (or even erases) blatant dehumanization. To investigate these issues, Canadian participants completed the "Ascent of Man" scale, rating various groups in terms of their perceived evolutionary qualities. Half of our participants saw labels with the qualifier "-Canadians" attached, while the other half saw no such qualifier. Results showed that, regardless of whether the "-Canadians" label was provided, participants rated Filipinos, Christians, Arabs, Muslims, and Indigenous groups as significantly lower than Whites on the evolution scale. As such, provision of the additional group label "-Canadians" did not influence the manifestation of blatant dehumanization. We also found that ratings on the evolution scale significantly correlated with both Social Dominance Orientation and Empathic Concern levels, such that stronger adherence to current power structures and social hierarchies showed stronger blatant dehumanization, while those with a high pre-disposition for altruistic behaviours and emotions showed weaker blatant dehumanization. We discuss our results in the light of other research on blatant dehumanization and intergroup processes.
\end{abstract}

Keywords: dehumanization, intergroup relations, dual identity, prejudice, pre-registered

\section{Introduction}

\subsection{Literature Review}

Dehumanization is colloquially defined as the process by which a person or group of people are deprived of human qualities. While previous psychological research has focused on dehumanization as an implicit and unconscious phenomenon that permeates everyday thoughts and behaviours (e.g., Leyen's et al., 2000; Viki et al., 2006; Bain et al., 2008), more recent work has emphasized the importance of empirically studying blatant dehumanization: the deliberate and conscious act of dehumanizing others (Kteily et al., 2015; Kteily \& Bruneau, 2017; but also see early work by Kelman, 1976; Opotow, 1990; Bandura, 1999). To empirically study dehumanization in non-pathological populations, Kteily et al. (2015) developed the "Ascent of Man" scale. This scale depicts five silhouettes starting with an ape-like creature and ending with a modern human, with the intervening silhouettes showcasing the physiological and cultural stages of human evolution. Participants are instructed to use the image to rate (via a slider) how evolved the average member of each group (e.g., Muslims) to be. Given the nature of this task, participants were explicitly aware of what they were doing, and their ratings could therefore be considered blatant dehumanization.

Using this scale, Kteily et al. (2015) first reported that American participants do indeed blatantly dehumanize some racial and religious groups (Study 1). Specifically, relative to the in-group category of American, significantly lower ratings were found for Chinese, South Korean, Mexican Immigrant, Arab, and Muslim (with these latter two categories showing the largest difference). Other groups such as Europeans, Swiss, and Japanese were not rated significantly lower than Americans, suggesting that the effects are not simply an 
in-group/out-group effect (minority groups in America, such as African Americans and Hispanic Americans, were also shown to be rated significantly lower in follow up work; see Kteily et al. (2015) Study 2). Kteily et al. (2015) also provided validity for the scale by showing that it correlated with a number of important self-report scales, such as Social Dominance Orientation (Pratto et al., 1994) and Right Wing Authoritarianism Scale (Altemeyer, 1996). In a series of follow-up studies, Kteily et al. (2015) replicated their original findings and extended them by showing that blatant dehumanization predicts negative attitudes (e.g., reducing Arab immigration), increases in the immediate aftermath of intergroup conflict (i.e., Boston Marathon bombing), generalizes to samples from other countries and region-specific intergroup attitudes (e.g., Hungarian dehumanization of the Roma), and predicts endorsement of punitive vs. transformative policies (especially towards hostile out-groups such as members of terror groups).

Numerous follow-up studies have corroborated and extended Kteily et al.'s (2015) original series of studies. For example, Kteily et al. (2016) showed that meta-dehumanization (i.e., knowing that one is being dehumanized by an outgroup) leads to reciprocal dehumanization; Kteily \& Bruneau (2017) found that blatant dehumanization of Mexican immigrants and Muslims predicted support for Republican policies and candidates (especially Donald Trump); Bruneau \& Kteily (2017) found that blatant dehumanization occurred for both Israelis (towards Palestinians) and Palestinians (towards Israelis) during the 2014 Gaza war, suggesting symmetrical dehumanization during an asymmetric conflict. As another example, Bruneau et al. (2018a) studied participants from Hungary, Greece, and Spain during the "Refugee Crisis" in Europe and found significant blatant dehumanization towards Muslim refugees. In addition, Bruneau et al. (2020a) provided evidence that intergroup contact can reduce blatant dehumanization.

In other recent work, Forscher \& Kteily (2020) report that participants categorized as "alt-right" showed significantly more blatant dehumanization towards derogated and opposition groups compared to other participants. Bruneau et al. (2020b) found that Hungarian teachers that showed the strongest levels of blatant dehumanization towards Roma minority students and preferentially placed such students into lower track schools. Finally, it has also been shown that people with mental illnesses can also be blatantly dehumanized (Boysen et al., 2020). An important question in trying to understand the nature of dehumanization is whether it is tantamount to simply disliking members of other groups. To investigate this issue, Bruneau et al. (2018b) ran a functional neuroimaging study and provided evidence of distinct neural networks underlying blatant dehumanization and simple dislike of an outgroup.

Overall, then, the current body of work on blatant dehumanization suggests that it is prevalent in modern society and has widespread consequences for attitudes and behaviours. An important question, then, is what factors lead to blatant humanization of out-groups? And relatedly, how can we reverse or reduce blatant dehumanization? As far as we are aware, only one study to date has explored this topic (Bruneau et al., 2020a as briefly described above). Bruneau et al. (2020a) provided strong evidence that intergroup contact can reduce blatant dehumanization. In their first study, they conducted a large-scale meta-analysis on survey data showing that the quality of intergroup contact predicted less blatant dehumanization and meta-dehumanization. In a second longitudinal study, they showed that the self-reported quality of contact with Muslims (but not quantity of contact) at time 1 predicted less blatant dehumanization at time 2. Lastly, in their third study they had non-Muslim American participants virtually engage with a Muslim participant for one semester and showed that both blatant dehumanization and meta-dehumanization decreased after the project (compared to scores obtained before the program started). This line of work strongly suggests that creating opportunities for positive intergroup contact is an effective way to decrease blatant dehumanization.

\subsection{The Current Study}

The current study adds to this line of research by exploring another possible method of decreasing blatant dehumanization: by making salient a shared in-group category. Many Western countries often have a diverse ethnic and religious make-up, especially in urban communities - this is also especially true in North America where major American and Canadian cities often have entire communities of immigrants (and the children of immigrants) from all over the world. How to promote harmony between different ethnic groups living in close proximity to one another is a major subject of research (Richeson \& Sommers, 2021). One possible method for promoting intergroup harmony is via the emphasis of having a dual identity - the simultaneous activation of concepts relating one's self to a particular group (e.g., Indian) while at the same time relating one's self to a superordinate group (e.g., Canadian). Such dual categorization of one's identity has been suggested to promote positive attitudes towards minorities (Dovidio et al., 2007; Banfield \& Dovidio, 2013). However, as far as we are aware, no study to date has explicitly tested whether activating a dual identity affects the tendency to engage in blatant dehumanization. Providing evidence that making salient a shared superordinate identity (e.g., "we are all 
Americans") can lower blatant dehumanization would offer practical insights on how to reduce the pernicious effects of dehumanization (although see Over, 2021 for a broader discussion including fewer negative effects of dehumanization).

As such, the aim of the current study is to conceptually replicate the basic dehumanization effects in a Canadian context and to examine whether the provision of a superordinate group identity label mitigates the tendency to blatantly dehumanize members of various social groups. To address these questions, we employ the Ascent of Man scale with a White Canadian sample. To manipulate the activation of a dual identity, half the participants were shown labels ending with -Canadians (e.g., Muslim-Canadians) while the other half saw labels without that qualifier (e.g., Muslims). We hypothesized that adding the label "Canadian" would make the superordinate category of "Canadians" salient and would therefore decrease blatant dehumanization. Note that we conjectured that this manipulation would be especially effective on a Canadian sample, as Canada has officially adopted an explicit multicultural policy regarding national identity (Note 1). To facilitate comparison of our findings with previous work (e.g., see Haslam \& Stratemeyer, 2016), we also asked participants to complete both the Social Dominance Orientation (SDO) scale and Interpersonal Reactivity Index (a measure of trait-levels of empathy; Davis, 1980; 1983).

\section{Methods}

\subsection{Pre-Registration}

Sample size and data analysis were pre-registered on AsPredicted.org: https://aspredicted.org/mg3v4.pdf

\subsection{Participants}

Sample size was determined via a Power Analysis using G*Power (Faul et al., 2007; 2009). For a $2 \times 15$ Mixed-Design ANOVA (see the Design section below), a sample size of 134 participants (67 per between-subjects condition) is needed to obtain $80 \%$ power to find a small (partial-eta^ $2=0.01$ ) effect size. As such, we collected data from 134 White Canadians (mean age $=34$; female $=64$ ) via Prolific - all participants were paid $£ 1.5$ for their time. Other than Nationality ("Canada") and Ethnicity ("White"), no other filters were set for recruitment - see Table 1. As per our pre-registration, participants that took less than $200 \mathrm{~ms}$ to respond to the Blatant Dehumanization Scale were removed - however, no participants met this criterion. Prior to participation, participants provided online informed consent. The study was approved by the university research ethics board.

Table 1. Demographic information of sample size.

\begin{tabular}{lllll}
\hline Sample Size & Nationality & Ethnicity & Gender & Mean Age \\
\hline $\mathrm{n}=134$ & Canadian & White & Female $=64$ & 34 \\
\hline
\end{tabular}

\subsection{Blatant Dehumanization Scale}

We used the same Ascent of Man Scale image and task instructions used by Kteily et al. (2015). Participants were instructed that they would be tasked with rating racial and religious groups on an evolution scale. Following Kteily et al. (2015), participants were prompted with the message: "People can vary in how human-like they seem. Some people seem highly evolved whereas others seem no different than lower animals. Using the image below, indicate on the slider how evolved you consider the average member this group to be". The slider always started on the lowest point of the scale - See Figure 1. Given that we were collecting Canadian participants, we opted to have participants rate nine racial categories representing some of the most common visible minorities (as well as the White majority) in Canadian society (Note 2): Whites, Blacks, Arabs, Chinese, Filipinos, South Asians, Koreans, Japanese, Indigenous. In addition, we also asked participants to rate six religion categories: Christian, Muslim, Sikh, Jewish, Hindu and Buddhist. All fifteen categories were rated one at a time and were presented randomly to each participant. 


\section{Arabs

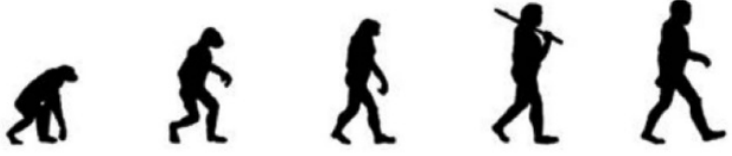

Figure 1. Example of a single trial of the Blatant Dehumanization task

\subsection{SDO and IRI}

Participants completed the 16-item SDO and 28-item IRI after they had completed the rating task using the Blatant Dehumanization Scale. The SDO is further split into two subscales: SDO-Dominance (SDO-D) and SDO-Egalitarian (SDO-E). SDO-D is thought to index more aggressive association with group hierarchies, SDO-E is thought to reflect subtle opposition to equality between groups. The IRI is split into four subscales: Perspective Taking (PT), Empathic Concern (EC), Personal Distress (PD), and the Fantasy Scale (FS). PT reflects the tendency or ability to adopt the point of view of other people, EC reflects the tendency to experience feelings of warmth, compassion and concern for others undergoing negative experiences, PD reflects the amount of discomfort and anxiety that occurs as a result of observing the negative experiences of others, and lastly, FS reflects the tendency to transpose or identify strongly with fictional characters (in movies, plays, books, etc.). Although only PT and EC reflect dispositional empathy, we report the other two subscales for completeness.

\subsection{Design and Data Analysis Plan}

The experiment used a $2 \times 15$ Mixed-Design ANOVA wherein Label (Dual Identity, Control) was the between-subjects factor and Group (Whites, Blacks, Arabs, Chinese, Filipinos, South Asians, Koreans, Japanese, Indigenous, Christians, Muslims, Sikhs, Jewish, Hindu, Buddhist) was the within-subjects factor. Participants in the Dual Identity condition saw each Group category with the added "-Canadian" qualifier (e.g., Muslim-Canadians). As per our pre-registration, all follow-up t-tests were conducted via Tukey's HSD to control for Type 1 error inflation.

\subsection{Procedure}

Participants were recruited via Prolific.co. After signing up for the study, they were given a link to the experiment website hosted on Pavlovia.org. Participants first saw a welcome page with information about the study. They were informed that continuing with the study after this page would be indicative of their consent to participate in the study. Afterwards, participants saw a brief instructions page about the Blatant Dehumanization task: "For this study, you will be tasked with categorizing racial and religious groups on an evolution scale. This scale is based on the perception that people can vary in how human-like they seem. Some people seem highly evolved whereas others seem no different than lower animals. All of your answers are anonymous, so please be honest in your ratings. Press Enter to start the study.”. Participants then rated the 15 groups on the Ascent of Man scale, one by one. After the task was complete, participants completed the SDO and IRI. Lastly, participants were asked about their religious affiliations at the end of the study. Once completed, participants were sent to a debrief page explaining the purpose of the study.

\section{Results}

\subsection{Blatant Dehumanization}

Note that the data violated the assumption of sphericity; as such, results are reported with a Greenhouse-Geisser correction. Data analysis was completed via Jamovi (ver. 1.6.8). The $2 \times 15$ Mixed-Design ANOVA showed a significant main effect of Group $\left[F(1,14)=10.17, p<0.001\right.$, partial-eta $\left.{ }^{\wedge} 2=0.07\right]$. The main effect of Label $[p>$ $0.06]$ and Group x Label interaction $[p>0.5]$ were non-significant. As per our pre-registration, we broke down 
the significant main effect of Group via Tukey's HSD to control for type 1 error inflation (as there are a large number of comparisons). The full breakdown of these post-hoc t-tests can be found in the supplementary materials. Following Kteily et al. (2015), however, we present here the post-hoc comparisons comparing Whites (the participants' in-groups) with all other categories, as these are the most relevant when interpreting the Blatant Dehumanization scale (to reiterate, these corrected p-values consider all possible comparisons via Tukey's HSD, not just the White vs. other categories comparisons). The post-hoc comparisons show that Filipinos, Christians, Arabs, Muslims, and Indigenous groups were significantly rated as lower than Whites [all $p<0.01$ ] - see Table 2. Jewish, Buddhists, Blacks, Koreans, Hindus, South Asians, Chinese, and Sikhs did not significantly differ from Whites [all $p>0.16$ ].

Table 2. Post-Hoc Comparisons Between Whites vs. Other Groups

\begin{tabular}{llll}
\hline Groups & Mean & Difference & Tukey HSD \\
\hline Whites & 95.6 & N/A & N/A \\
Japanese & 96.1 & -0.56 & $>0.99$ \\
Jewish & 96.0 & -0.44 & $>0.99$ \\
Buddhists & 94.3 & 1.29 & $>0.99$ \\
Blacks & 93.9 & 1.67 & $>0.99$ \\
Koreans & 93.1 & 2.43 & $>0.83$ \\
Hindus & 93.1 & 2.52 & $>0.78$ \\
South Asians & 92.9 & 2.66 & $>0.71$ \\
Chinese & 92.2 & 3.37 & $>0.31$ \\
Sikhs & 91.9 & 3.72 & $>0.16$ \\
Filipinos & 90.3 & 5.25 & $=0.002^{* *}$ \\
Christians & 89.7 & 5.84 & $<0.001^{* * *}$ \\
Arabs & 89.4 & 6.23 & $<0.001^{* * *}$ \\
Muslims & 88.5 & 7.10 & $<0.001^{* * *}$ \\
Indigenous & 86.8 & 8.77 & $<0.001^{* * *}$ \\
\hline **p $<0.01 ; * * \mathrm{p}<0.001$ & &
\end{tabular}

\section{$3.2 S D O$ and IRI}

To correlate the SDO and IRI subscales to Blatant Dehumanization, we follow Kteily et al. (2015) in creating a Dehumanization Index via the average difference between Whites and the lowest rated groups (i.e., Filipinos, Christians, Arabs, Muslims, and Indigenous). Note that participants could freely choose not to answer any item from the SDO or IRI, as such sample size fluctuates for these correlations. For transparency, we report sample size for each analysis. For the SDO, our results showed that both SDO-D $[r=0.32, p<0.001, \mathrm{n}=131]$ and SDO-E $[r=0.26, p=0.002, \mathrm{n}=133]$ significantly correlated with the Dehumanization Index; for the IRI, we found that only EC $[r=-0.28, p=0.001, \mathrm{n}=132]$ significantly correlated with the Dehumanization Index - See Table 3. The PT $[r=-0.13, p>0.14, \mathrm{n}=133]$, PD $[r=-0.11, p>0.21, \mathrm{n}=132]$, and FS $[r=-0.013, p>0.88, \mathrm{n}$ $=134]$ subscales were non-significant.

Table 3. Correlations Between Humanization Index and SDO/IRI

\begin{tabular}{lll}
\hline Scale & r-value & $\mathrm{p}$-value \\
\hline SDO-D & 0.32 & $<0.001^{* * *}$ \\
SDO-E & 0.26 & $=0.002^{* *}$ \\
EC & -0.28 & $=0.001^{* *}$ \\
PT & -0.13 & $>0.14$ \\
PD & -0.11 & $>0.21$ \\
FS & -0.01 & $>0.88$ \\
\hline$* * \mathrm{p}<0.01 ; * * * \mathrm{p}<0.001$ &
\end{tabular}

\section{Discussion}

The aim of the current study was to investigate the potential effects of activating a dual identity on blatant dehumanization within the Canadian context. We predicted that White Canadians would be less inclined to 
blatantly dehumanize other groups if such groups were labelled as also Canadian (e.g., "Muslim-Canadians"). Contrary to this prediction, we found that blatant dehumanization occurred regardless of group labels being qualified with "-Canadian". Specifically, we found a significant main effect of Group which showed that our White Canadian participants rated Filipinos, Christians, Arabs, Muslims, and Indigenous peoples as significantly less evolved compared to Whites. These results are important, as this suggests that merely labelling an out-group with a shared superordinate group label may not override negative associations with the out-group label. This implies that merely reminding people of their shared identity in text-based stimuli may not be an effective strategy for alleviating dehumanization.

Given the possibility that merely showing labels is not a strong enough manipulation to make salient a shared superordinate category, other methods should be considered. For example, visual cues such as a picture of a person holding a Canadian flag or wearing a Canadian military uniform may have provided a stronger method for making salient a shared superordinate category. Furthermore, unlike Bruneau et al. (2020a), we did not collect data pertaining to participant experiences with each of these out-groups. Given that the many visible minorities in Canada live in large cities in populous provinces, it is possible that a lack of contact or experience with members of these visible minorities meant that merely labelling them as "Canadian" rang hollow for some participants (unfortunately Prolific does not provide this sort of geographic data for Canadian participants). An interesting future study, then, is to explore how the quantity and quality of intergroup contact (within a country) leads to the creation of a shared national identity, and whether such a shared superordinate group influences blatant dehumanization above and beyond the quality of the intergroup contact (i.e., Bruneau et al., 2020a). There is ample evidence from research on contact theory in relation to other forms of bias and prejudice that provides a solid basis for expanding work on mitigating dehumanization (Dovidio et al., 2017; see also Haslam \& Stratemeyer, 2016)

Regarding the lowest rated out-groups, the results are troubling, but not surprising given the lived experiences of many members of certain social groups. While it is impossible to pinpoint exactly why our sample of White Canadians rated specific groups (Filipinos, Christians, Arabs, Muslims, and Indigenous peoples) as less evolved compared to Whites, it is possible to speculate about some possible causes. For example, while Filipinos are the fastest growing immigrant population in Canada, many often immigrate to take on service jobs to send money to family still in the Philippines (Note 1), which perhaps leads to a perception of them being lower class in Canadian society.

Regarding Muslims and Arabs, negative perceptions from some Canadians have tended to mirror those of their American neighbours, with hate crimes against Muslim-Canadians rising in recent years (Note 3) (Note 4). Indeed, since the "war on terror" in the post 9-11 years, Muslims and Arabs in North America have routinely faced suspicion, prejudice and acts of horrific violence. In the Canadian context this is exemplified by the attack on a Mosque in Quebec City in 2017 in which six worshippers were murdered by a White man (Mahrouse, 2018). Indeed, anti-Islamic rhetoric continues to be common on social media and in western society at large (Kwon et al., 2019; Horsti, 2017).

Lastly, the history of Colonialism in Canada and the manner in which Indigenous cultures have been and continue to be seen and framed through the colonial lens may have had a dehumanizing effect and thus contributed to the results of the current study. Residential schools are just one horrific example of the dehumanizing and inhumane treatment that many Indigenous peoples have faced even during relatively recent times. Indeed, tensions between Canadians (especially White Canadians) and Indigenous peoples in Canada have historically been high (e.g., recent national movements such as Idle No More, Prime Minister Trudeau's national apology to residential school survivors on behalf of Canada and some White politicians even denying the damage that residential schools did (Note 5)). Such historical tensions, rooted in colonialism, contribute to the continued negative perceptions of Indigenous peoples in Canada today (e.g., Allan \& Smylie, 2015). Such negative perceptions may have been reflected by our sample of White Canadian participants dehumanizing Indigenous peoples to a greater extent than other social groups.

It is also possible that, in the context of the way that Kteily et al. (2015) phrased the instructions for studies using the ascent of man scale (instructions that we adopted in the present study), participants think about the concept of "evolved" in specific ways for Indigenous versus other groups. This could be related to stereotypes about Indigenous peoples having tribal cultures that are seen as primitive and outdated (Wylie \& McConkey, 2019). Again, such stereotypes have their roots in Canada's colonial past, in which Indigenous Peoples were cast as inferior to White Europeans and subjected to horrific violence and inhumane treatment. Overall, our results suggest that Indigenous peoples fair worse in terms of the extent to which they are blatantly dehumanized compared to other social groups in Canada. 
One surprising result is the fact that Christians as a group were rated significantly lower compared to Whites. However, this could be explained by the fact that the majority of our participants identified as non-religious $(\mathrm{n}=$ 87). Indeed, when only analyzing data from our Christian participants $(n=33)$, there is no longer a significant difference between Christians and Whites. This suggests that non-religious participants are specifically biased against Christians compared to other religious groups; however, as this finding is post-hoc and not a part of the original motivations of this study, future work will be needed to more fully explore this topic.

In addition to the finding that Christians as a group were rated as less evolved than Whites, it may also be surprising that Blacks were not rated significantly lower than Whites, especially given the documented existence of racism towards Black people in Canada (e.g., Mullings et al., 2016; Gupta, 1996). However, given the timing of our study and the fact that awareness of anti-Black racism is perhaps at its highest levels around the world, it is also possible that this is due to recent events related to the Black Lives Matter movement (a salient topic during data collection). The BLM movement has made salient the reality of racial bias against Blacks (both in Canada, the United States and more broadly). Furthermore, BLM has garnered support from many White people in North America and around the globe. It is possible that these recent social trends helped foster awareness in our White Canadian participants of the biases towards Blacks, and that, in this context, they tried to mitigate bias by rating Blacks similarly to Whites. It is also possible that dehumanization per se of Blacks in Canada is different from dehumanization of Blacks in the US, given the different histories of the two nations. It is theoretically possible that even if blatant dehumanization of Blacks is lower in Canada, other forms of bias and prejudice in Canada may persist. Ultimately, more work will be needed to fully elucidate the contrast between how blatant dehumanization affects Blacks in Canada, the US and elsewhere.

Importantly, our results also showed that SDO-D, SDO-E, and EC significantly correlated with participant's humanization index. Both the SDO-D and SDO-E positively correlated with the humanization index, suggesting that larger differences between Whites and the lowest rated out-groups was predicted by higher scores on SDO-D and SDO-E. In contrast, we found a negative correlation between EC and the humanization index, showing that higher levels of empathic concern were associated with smaller differences between Whites and the lower rated out-groups.

Overall, then, participants that support the current power structures and social hierarchies showed stronger blatant dehumanization, while those with a high pre-disposition for altruistic behaviours and emotions showed weaker blatant dehumanization. These results corroborate Kteily et al.'s (2015) findings within our Canadian context, and provide convergent validity of the scale used in this study.

In conclusion, the current study sought to explore the possible alleviating effects of activating a dual identity on blatant dehumanization. Contrary to our expectations, qualifying out-group categories with "-Canadian" did not influence the manifestation of blatant dehumanization. This may suggest that simply reminding participants of a shared superordinate category is not a powerful enough approach to weaken out-group bias, at least in the form of blatant dehumanization. However, we also suggested future lines of research to further explore this topic. Our findings are also important as they extend recent work on blatant dehumanization by confirming its existence in a Canadian context. Specifically, blatant dehumanization in Canada was evident when White Canadians rated Filipinos, Christians, Muslims, Arabs, and Indigenous peoples as less evolved compared to Whites. This perception appears to be associated with both SDO and EC. Although we report a disturbing and troublesome finding, the current study nevertheless provides us with further insights on the ubiquitous nature of blatant dehumanization in modern society. Indeed, the fact that blatant dehumanization persists in a country like Canada, which is well known for its policies promoting multiculturalism and respect for difference, reminds us that creating a more diverse, equitable and inclusive society, is an ongoing journey.

\section{Acknowledgements}

This work was supported by a SSHRC Insight Grant, along with infrastructure funding from the Canada Foundation for Innovation, held by SSO. The authors wish to express sincere thanks to Sage Hartmann for useful feedback on an earlier version of this manuscript and Prof. Adrianne Xavier (acting Director of the Indigenous Studies Program at McMaster University), for helpful discussion and feedback.

\section{Conflicts of Interest}

The authors declare no conflicts of interest.

\section{References}

Allan, B., \& Smylie, J. (2015). First Peoples, second class treatment: The role of racism in the health and well-being of Indigenous peoples in Canada. Toronto, ON: the Wellesley Institute. 
Altemeyer, B. (1996). The authoritarian specter. Cambridge, MA: Harvard University Press.

Bain, P., Park, J., Kwok, C., \& Haslam, N. (2009). Attributing human uniqueness and human nature to cultural groups: Distinct forms of subtle dehumanization. Group Processes \& Intergroup Relations, 12, 789-805. https://doi.org/10.1177/1368430209340415

Bandura, A. (1999). Moral disengagement in the perpetration of inhumanities. Personality and Social Psychology Review, 3, 193-209. https://doi.org/10.1207/s15327957pspr0303_3

Banfield, J. C., \& Dovidio, J. F. (2013). Whites' perceptions of discrimination against Blacks: the influence of common identity. Journal of Experimental Social Psychology, 49(5), 833-841. https://doi.org/10.1016/j.jesp.2013.04.008

Boysen, G. A., Isaacs, R. A., Tretter, L., \& Markowski, S. (2020). Evidence for blatant dehumanization of mental illness and its relation to stigma. Journal of Social Psychology, 160(3), 346-356. https://doi.org/10.1080/00224545.2019.1671301

Bruneau, E., \& Kteily, N. (2017). The enemy as animal: Symmetric dehumanization during asymmetric warfare. PLoS ONE, 12(7), e0181422. https://doi.org/10.1371/journal.pone.0181422

Bruneau, E., Hameiri, B., Moore-Berg, S. L., \& Kteily, N. (2020a). Intergroup Contact Reduces Dehumanization and Meta-Dehumanization: Cross-Sectional, Longitudinal, and Quasi-Experimental Evidence From 16 Samples in Five Countries. Personality and Social Psychology Bulletin, 1-15. https://doi.org/10.1177/0146167220949004

Bruneau, E., Jacoby, N., Kteily, N., \& Saxe, R. (2018b). Denying Humanity: The Distinct Neural Correlates of Blatant Dehumanization. Journal of Experimental Psychology: General, 147(7), 1078-1093. https://doi.org/10.1037/xge0000417

Bruneau, E., Kteily, N., \& Laustsen, L. (2018a). The unique effects of blatant dehumanization on attitudes and behavior towards Muslim refugees during the European 'refugee crisis' across four countries. European Journal of Social Psychology, 48(5), 645-666. https://doi.org/10.1002/ejsp.2357

Bruneau, E., Szekeres, H., Kteily, N., Tropp, L. R., \& Kende, A. (2020b). Beyond dislike: Blatant dehumanization predicts teacher discrimination. Group Processes \& Intergroup Relations, 23(4), 560-577. https://doi.org/10.1177/1368430219845462

Davis, M. H. (1980). A Multidimensional Approach to individual differences in empathy. JASAS Catalog of Selected Documents in Psychology, 10, 85-104.

Davis, M. H. (1983). Measuring individual differences in empathy: Evidence for a Multidimensional Approach. Journal of Personality and Social Psychology, 44(1), 113-126. https://doi.org/10.1037/0022-3514.44.1.113

Dovidio, J. F., Love, A., Schellhaas, F. M. H., \& Hewstone, M. (2017). Reducing intergroup bias through intergroup contact: Twenty years of progress and future directions. Group Processes \& Intergroup Relations, 20(5), 606-620. https://doi.org/10.1177/1368430217712052

Dovidio, J. F., Gaertner, S. L., \& Saguy, T. (2007). Another view of "we": majority and minority group perspectives on a common ingroup identity. European Review of Social Psychology, 18(1), 296-330. https://doi.org/10.1080/10463280701726132

Faul, F., Erdfelder, E., Buchner, A., \& Lang, A.-G. (2009). Statistical power analyses using G*Power 3.1: Tests for correlation and regression analyses. Behavior Research Methods, 41, 1149-1160. https://doi.org/10.3758/BRM.41.4.1149

Faul, F., Erdfelder, E., Lang, A.-G., \& Buchner, A. (2007). G*Power 3: A flexible statistical power analysis program for the social, behavioral, and biomedical sciences. Behavior Research Methods, 39, 175-191. https://doi.org/10.3758/BF03193146

Forscher, P. S., \& Kteily, N. (2020). A Psychological Profile of the Alt-Right. Perspectives on Psychological Science, 15(1), 90-116. https://doi.org/10.1177/1745691619868208

Haslam, N., \& Stratemeyer, M. (2016). Recent research on dehumanization. Current Opinion in Psychology, 11, 25-29. https://doi.org/10.1016/j.copsyc.2016.03.009

Kelman, H. (1976). Violence without restraint: Reflections on the dehumanization of victims and victimizers. In G. Kren \& L. Rappoport (Eds.), Varieties of psychohistory (pp. 282-314). New York, NY: Springer. 
Kteily, N., \& Bruneau, E. (2017). Backlash: The Politics and Real-World Consequences of Minority Group Dehumanization. Personality and Social Psychology Bulletin, 43(1), 87-104. https://doi.org/10.1177/0146167216675334

Kteily, N., \& Bruneau, E. (2017). Darker Demons of Our Nature: the Need to (Re)Focus Attention on Blatant Forms of Dehumanization. Current Directions in Psychological Science, 26(6), 487-494. https://doi.org/10.1177/0963721417708230

Kteily, N., Bruneau, E., Waytz, A., \& Cotterill, S. (2015). The ascent of man: Theoretical and empirical evidence for blatant dehumanization. Journal of Personality and Social Psychology, 109, 901-931. https://doi.org/10.1037/pspp0000048

Kteily, N., Hodson, G., \& Bruneau, E. (2016). They see us as less than human: Metadehumanization predicts intergroup conflict via reciprocal dehumanization. Journal of Personality and Social Psychology, 110(3), 343-370. https://doi.org/10.1037/pspa0000044

Leyens, J., Paladino, P. M., Rodriguez-Torres, R., Vaes, J., Demoulin, S., Rodriguez-Perez, A., \& Gaunt, R. (2000). The emotional side of prejudice: The attribution of secondary emotions to ingroups and outgroups. Personality and Social Psychology Review, 4, 186-197. https://doi.org/10.1207/S15327957PSPR0402_06

Mahrouse, G. (2018). Minimizing and denying racial violence: Insights from the Québec mosque shooting. Canadian Journal of Women and the Law, 30(3), 471-493. https://doi.org/10.3138/cjwl.30.3.006

Opotow, S. (1990). Moral exclusion and injustice: An introduction. Journal of Social Issues, 46, 1-20. https://doi.org/10.1111/j.1540-4560.1990.tb00268.x

Over, H. (2021). Seven Challenges for the Dehumanization Hypothesis. Perspectives on Psychological Science, 16(1), 3-13. https://doi.org/10.1177/1745691620902133

Pratto, F., Sidanius, J., Stallworth, L. M., \& Malle, B. F. (1994). Social dominance orientation: A personality variable predicting social and political attitudes. Journal of Personality and Social Psychology, 67, 741-763. https://doi.org/10.1037//0022-3514.67.4.741

Richeson, J. A., \& Sommers, S. R. (2016). Toward a Social Psychology of Race and Race Relations for the Twenty-First Century. Annual Review of Psychology, 67, 439-463. https://doi.org/10.1146/annurev-psych-010213-115115

Viki, G., Winchester, L., Titshall, L., Chisango, T., Pina, A., \& Russell, R. (2006). Beyond secondary emotions: The infrahumanization of outgroups using human-related and animal-related words. Social Cognition, 24, 753-775. https://doi.org/10.1521/soco.2006.24.6.753

Wylie, L., \& McConkey, S. (2019). Insiders' Insight: Discrimination against Indigenous Peoples through the Eyes of Health Care Professionals. Journal of Racial and Ethnic Health Disparities, 6(37), 37-45. https://doi.org/10.1007/s40615-018-0495-9

\section{Notes}

Note 1. See: https://www.canada.ca/en/services/culture/canadian-identity-society/multiculturalism.html

Note 2. 2016 Census: https://www23.statcan.gc.ca/imdb/p3Var.pl?Function=DECI\&Id=257515

Note 3. See: https://ottawape.dfa.gov.ph/index.php/2016-04-12-08-34-55/filipino-diaspora

Note 4. Also see: https://angusreid.org/canadians-view-non-christian-religions-with-uncertainty-dislike/

Note

https://www.cbc.ca/news/politics/residential-school-system-well-intentioned-conservative-senator-1.4015115 


\section{Appendix}

Supplementary Table 1

Full Post-Hoc Comparisons via Tukey's HSD (created via Jamovi ver. 1.6.8)

Post Hoc Comparisons - Groups

\begin{tabular}{|c|c|c|c|c|c|c|c|}
\hline \multicolumn{3}{|c|}{ Comparison } & \multirow[b]{2}{*}{ Mean Difference } & \multirow[b]{2}{*}{$\mathbf{S E}$} & \multirow[b]{2}{*}{ df } & \multirow[b]{2}{*}{$\mathbf{t}$} & \multirow[b]{2}{*}{ p $_{\text {tukey }}$} \\
\hline Groups & & Groups & & & & & \\
\hline \multirow[t]{14}{*}{ Whites } & - & Jewish & -0.4403 & 1.25 & 1848 & -0.3516 & 1.00000 \\
\hline & - & Japanese & -0.5522 & 1.25 & 1848 & -0.4410 & 1.00000 \\
\hline & - & Buddhists & 1.2985 & 1.25 & 1848 & 1.0370 & 0.99945 \\
\hline & - & Blacks & 1.6716 & 1.25 & 1848 & 1.3350 & 0.99202 \\
\hline & - & Koreans & 2.4328 & 1.25 & 1848 & 1.9429 & 0.83101 \\
\hline & - & Hindus & 2.5224 & 1.25 & 1848 & 2.0144 & 0.78991 \\
\hline & - & South Asians & 2.6642 & 1.25 & 1848 & 2.1276 & 0.71627 \\
\hline & - & Chinese & 3.3731 & 1.25 & 1848 & 2.6938 & 0.30933 \\
\hline & - & Sikhs & 3.7239 & 1.25 & 1848 & 2.9739 & 0.16471 \\
\hline & - & Filipinos & 5.2537 & 1.25 & 1848 & 4.1956 & 0.00263 \\
\hline & - & Christians & 5.8358 & 1.25 & 1848 & 4.6605 & 0.00033 \\
\hline & - & Arabs & 6.2313 & 1.25 & 1848 & 4.9763 & 0.00007 \\
\hline & - & Muslims & 7.1045 & 1.25 & 1848 & 5.6736 & $<.00001$ \\
\hline & - & Indigenous & 8.7761 & 1.25 & 1848 & 7.0086 & $<.00001$ \\
\hline \multirow[t]{13}{*}{ Jewish } & - & Japanese & -0.1119 & 1.25 & 1848 & -0.0894 & 1.00000 \\
\hline & - & Buddhists & 1.7388 & 1.25 & 1848 & 1.3886 & 0.98833 \\
\hline & - & Blacks & 2.1119 & 1.25 & 1848 & 1.6866 & 0.93727 \\
\hline & - & Koreans & 2.8731 & 1.25 & 1848 & 2.2945 & 0.59482 \\
\hline & - & Hindus & 2.9627 & 1.25 & 1848 & 2.3660 & 0.54073 \\
\hline & - & South Asians & 3.1045 & 1.25 & 1848 & 2.4792 & 0.45599 \\
\hline & - & Chinese & 3.8134 & 1.25 & 1848 & 3.0454 & 0.13726 \\
\hline & - & Sikhs & 4.1642 & 1.25 & 1848 & 3.3255 & 0.06217 \\
\hline & - & Filipinos & 5.6940 & 1.25 & 1848 & 4.5472 & 0.00056 \\
\hline & - & Christians & 6.2761 & 1.25 & 1848 & 5.0121 & 0.00006 \\
\hline & - & Arabs & 6.6716 & 1.25 & 1848 & 5.3279 & 0.00001 \\
\hline & - & Muslims & 7.5448 & 1.25 & 1848 & 6.0252 & $<.00001$ \\
\hline & - & Indigenous & 9.2164 & 1.25 & 1848 & 7.3602 & $<.00001$ \\
\hline Japanese & - & Buddhists & 1.8507 & 1.25 & 1848 & 1.4780 & 0.97924 \\
\hline
\end{tabular}


Post Hoc Comparisons - Groups

\begin{tabular}{|c|c|c|c|c|c|c|c|}
\hline \multicolumn{3}{|c|}{ Comparison } & \multirow[b]{2}{*}{ Mean Difference } & \multirow[b]{2}{*}{ SE } & \multirow[b]{2}{*}{ df } & \multirow[b]{2}{*}{$\mathbf{t}$} & \multirow[b]{2}{*}{$\mathbf{p}_{\text {tukey }}$} \\
\hline Groups & & Groups & & & & & \\
\hline & - & Blacks & 2.2239 & 1.25 & 1848 & 1.7760 & 0.90766 \\
\hline & - & Koreans & 2.9851 & 1.25 & 1848 & 2.3839 & 0.52721 \\
\hline & - & Hindus & 3.0746 & 1.25 & 1848 & 2.4554 & 0.47359 \\
\hline & - & South Asians & 3.2164 & 1.25 & 1848 & 2.5686 & 0.39192 \\
\hline & - & Chinese & 3.9254 & 1.25 & 1848 & 3.1348 & 0.10803 \\
\hline & - & Sikhs & 4.2761 & 1.25 & 1848 & 3.4149 & 0.04709 \\
\hline & - & Filipinos & 5.8060 & 1.25 & 1848 & 4.6366 & 0.00037 \\
\hline & - & Christians & 6.3881 & 1.25 & 1848 & 5.1015 & 0.00004 \\
\hline & - & Arabs & 6.7836 & 1.25 & 1848 & 5.4173 & $<.00001$ \\
\hline & - & Muslims & 7.6567 & 1.25 & 1848 & 6.1146 & $<.00001$ \\
\hline & - & Indigenous & 9.3284 & 1.25 & 1848 & 7.4496 & $<.00001$ \\
\hline \multirow[t]{11}{*}{ Buddhists } & - & Blacks & 0.3731 & 1.25 & 1848 & 0.2980 & 1.00000 \\
\hline & - & Koreans & 1.1343 & 1.25 & 1848 & 0.9059 & 0.99989 \\
\hline & - & Hindus & 1.2239 & 1.25 & 1848 & 0.9774 & 0.99972 \\
\hline & - & South Asians & 1.3657 & 1.25 & 1848 & 1.0906 & 0.99904 \\
\hline & - & Chinese & 2.0746 & 1.25 & 1848 & 1.6568 & 0.94545 \\
\hline & - & Sikhs & 2.4254 & 1.25 & 1848 & 1.9369 & 0.83423 \\
\hline & - & Filipinos & 3.9552 & 1.25 & 1848 & 3.1586 & 0.10113 \\
\hline & - & Christians & 4.5373 & 1.25 & 1848 & 3.6235 & 0.02356 \\
\hline & - & Arabs & 4.9328 & 1.25 & 1848 & 3.9393 & 0.00739 \\
\hline & - & Muslims & 5.8060 & 1.25 & 1848 & 4.6366 & 0.00037 \\
\hline & - & Indigenous & 7.4776 & 1.25 & 1848 & 5.9716 & $<.00001$ \\
\hline \multirow[t]{9}{*}{ Blacks } & - & Koreans & 0.7612 & 1.25 & 1848 & 0.6079 & 1.00000 \\
\hline & - & Hindus & 0.8507 & 1.25 & 1848 & 0.6794 & 1.00000 \\
\hline & - & South Asians & 0.9925 & 1.25 & 1848 & 0.7926 & 0.99998 \\
\hline & - & Chinese & 1.7015 & 1.25 & 1848 & 1.3588 & 0.99052 \\
\hline & - & Sikhs & 2.0522 & 1.25 & 1848 & 1.6389 & 0.94997 \\
\hline & - & Filipinos & 3.5821 & 1.25 & 1848 & 2.8606 & 0.21600 \\
\hline & - & Christians & 4.1642 & 1.25 & 1848 & 3.3255 & 0.06217 \\
\hline & - & Arabs & 4.5597 & 1.25 & 1848 & 3.6414 & 0.02214 \\
\hline & - & Muslims & 5.4328 & 1.25 & 1848 & 4.3386 & 0.00143 \\
\hline
\end{tabular}


Post Hoc Comparisons - Groups

\begin{tabular}{|c|c|c|c|c|c|c|c|}
\hline \multicolumn{3}{|l|}{ Comparison } & \multirow[b]{2}{*}{ Mean Difference } & \multirow[b]{2}{*}{ SE } & \multirow[b]{2}{*}{ df } & \multirow[b]{2}{*}{$\mathbf{t}$} & \multirow[b]{2}{*}{ Ptukey } \\
\hline Groups & & Groups & & & & & \\
\hline & - & Indigenous & 7.1045 & 1.25 & 1848 & 5.6736 & $<.00001$ \\
\hline \multirow[t]{9}{*}{ Koreans } & - & Hindus & 0.0896 & 1.25 & 1848 & 0.0715 & 1.00000 \\
\hline & - & South Asians & 0.2313 & 1.25 & 1848 & 0.1847 & 1.00000 \\
\hline & - & Chinese & 0.9403 & 1.25 & 1848 & 0.7509 & 0.99999 \\
\hline & - & Sikhs & 1.2910 & 1.25 & 1848 & 1.0310 & 0.99949 \\
\hline & - & Filipinos & 2.8209 & 1.25 & 1848 & 2.2528 & 0.62608 \\
\hline & - & Christians & 3.4030 & 1.25 & 1848 & 2.7176 & 0.29475 \\
\hline & - & Arabs & 3.7985 & 1.25 & 1848 & 3.0335 & 0.14158 \\
\hline & - & Muslims & 4.6716 & 1.25 & 1848 & 3.7308 & 0.01612 \\
\hline & - & Indigenous & 6.3433 & 1.25 & 1848 & 5.0657 & 0.00005 \\
\hline \multirow[t]{8}{*}{ Hindus } & - & South Asians & 0.1418 & 1.25 & 1848 & 0.1132 & 1.00000 \\
\hline & - & Chinese & 0.8507 & 1.25 & 1848 & 0.6794 & 1.00000 \\
\hline & - & Sikhs & 1.2015 & 1.25 & 1848 & 0.9595 & 0.99978 \\
\hline & - & Filipinos & 2.7313 & 1.25 & 1848 & 2.1812 & 0.67848 \\
\hline & - & Christians & 3.3134 & 1.25 & 1848 & 2.6461 & 0.33965 \\
\hline & - & Arabs & 3.7090 & 1.25 & 1848 & 2.9620 & 0.16965 \\
\hline & - & Muslims & 4.5821 & 1.25 & 1848 & 3.6592 & 0.02079 \\
\hline & - & Indigenous & 6.2537 & 1.25 & 1848 & 4.9942 & 0.00007 \\
\hline \multirow[t]{7}{*}{ South Asians } & - & Chinese & 0.7090 & 1.25 & 1848 & 0.5662 & 1.00000 \\
\hline & - & Sikhs & 1.0597 & 1.25 & 1848 & 0.8463 & 0.99995 \\
\hline & - & Filipinos & 2.5896 & 1.25 & 1848 & 2.0680 & 0.75621 \\
\hline & - & Christians & 3.1716 & 1.25 & 1848 & 2.5329 & 0.41713 \\
\hline & - & Arabs & 3.5672 & 1.25 & 1848 & 2.8487 & 0.22197 \\
\hline & - & Muslims & 4.4403 & 1.25 & 1848 & 3.5460 & 0.03068 \\
\hline & - & Indigenous & 6.1119 & 1.25 & 1848 & 4.8810 & 0.00012 \\
\hline \multirow[t]{6}{*}{ Chinese } & - & Sikhs & 0.3507 & 1.25 & 1848 & 0.2801 & 1.00000 \\
\hline & - & Filipinos & 1.8806 & 1.25 & 1848 & 1.5018 & 0.97607 \\
\hline & - & Christians & 2.4627 & 1.25 & 1848 & 1.9667 & 0.81783 \\
\hline & - & Arabs & 2.8582 & 1.25 & 1848 & 2.2826 & 0.60379 \\
\hline & - & Muslims & 3.7313 & 1.25 & 1848 & 2.9798 & 0.16227 \\
\hline & - & Indigenous & 5.4030 & 1.25 & 1848 & 4.3148 & 0.00158 \\
\hline
\end{tabular}


Post Hoc Comparisons - Groups

\begin{tabular}{|c|c|c|c|c|c|c|c|}
\hline \multicolumn{3}{|c|}{ Comparison } & \multirow[b]{2}{*}{ Mean Difference } & \multirow[b]{2}{*}{ SE } & \multirow[b]{2}{*}{ df } & \multirow[b]{2}{*}{$\mathbf{t}$} & \multirow[b]{2}{*}{ p tukey $_{1}$} \\
\hline Groups & & Groups & & & & & \\
\hline \multirow[t]{5}{*}{ Sikhs } & - & Filipinos & 1.5299 & 1.25 & 1848 & 1.2217 & 0.99674 \\
\hline & - & Christians & 2.1119 & 1.25 & 1848 & 1.6866 & 0.93727 \\
\hline & - & Arabs & 2.5075 & 1.25 & 1848 & 2.0025 & 0.79707 \\
\hline & - & Muslims & 3.3806 & 1.25 & 1848 & 2.6997 & 0.30565 \\
\hline & - & Indigenous & 5.0522 & 1.25 & 1848 & 4.0347 & 0.00508 \\
\hline \multirow[t]{4}{*}{ Filipinos } & - & Christians & 0.5821 & 1.25 & 1848 & 0.4649 & 1.00000 \\
\hline & - & Arabs & 0.9776 & 1.25 & 1848 & 0.7807 & 0.99998 \\
\hline & - & Muslims & 1.8507 & 1.25 & 1848 & 1.4780 & 0.97924 \\
\hline & - & Indigenous & 3.5224 & 1.25 & 1848 & 2.8130 & 0.24053 \\
\hline \multirow[t]{3}{*}{ Christians } & - & Arabs & 0.3955 & 1.25 & 1848 & 0.3159 & 1.00000 \\
\hline & - & Muslims & 1.2687 & 1.25 & 1848 & 1.0131 & 0.99958 \\
\hline & - & Indigenous & 2.9403 & 1.25 & 1848 & 2.3481 & 0.55427 \\
\hline \multirow[t]{2}{*}{ Arabs } & - & Muslims & 0.8731 & 1.25 & 1848 & 0.6973 & 1.00000 \\
\hline & - & Indigenous & 2.5448 & 1.25 & 1848 & 2.0322 & 0.77893 \\
\hline Muslims & - & Indigenous & 1.6716 & 1.25 & 1848 & 1.3350 & 0.99202 \\
\hline
\end{tabular}

\section{Copyrights}

Copyright for this article is retained by the author(s), with first publication rights granted to the journal.

This is an open-access article distributed under the terms and conditions of the Creative Commons Attribution license (http://creativecommons.org/licenses/by/4.0/). 